\title{
Development of a New Cellular Solid Breeder for Enhanced Tritium Production
}

\author{
Shahram Sharafat ${ }^{\mathrm{a}^{*}}$, Brian Williams ${ }^{\mathrm{b}}$, Nasr Ghoniem ${ }^{\mathrm{a}}$, Adam Ghoniem ${ }^{\mathrm{c}}$, Masashi Shimada ${ }^{\mathrm{d}}$, \\ and Alice Ying ${ }^{\mathrm{a}}$ \\ ${ }^{a}$ University of California Los Angeles, 420 Westwood Pl., Los Angeles, CA 90095-1587, U.S.A. \\ ${ }^{b}$ Ultramet, Pacoima, CA 91331-2210, U.S.A. \\ ${ }^{c}$ Digital Materials Solutions, Inc., Westwood, CA 90024, U.S.A. \\ ${ }^{d}$ Idaho National Laboratory, Idaho Falls, ID 83415, USA.
}

\begin{abstract}
A new high-performance cellular solid breeder is presented that has several times the thermal conductivity and is substantially denser compared with sphere-packed breeder beds. The cellular breeder is fabricated using a patented process of melt-infiltrating ceramic breeder material into an open-cell carbon foam. Following solidification the carbon foam is removed by oxidation. This process results in a near $90 \%$ dense robust freestanding breeder in a block configuration with an internal network of open interconnected micro-channels for tritium release. The network of interconnected micro-channels was investigated using X-ray tomography. Aside from increased density and thermal conductivity relative to pebble beds, high temperature sintering is eliminated and thermal durability is increased. Cellular breeder morphology, thermal conductivity, specific heat, porosity levels, high temperature mechanical properties, and deuterium charging-desorption rates are presented.
\end{abstract}

Keywords: cellular solid breeder, melt-infiltrated, micro-channels, interconnected porosity, enhanced tritium production.

\section{Introduction}

Lithium-containing ceramic breeder materials have been under development for several decades as a tritium breeding material and to convert energy into heat in solid breeder blankets. Early blanket conceptual design activities considered bulk ceramic breeder materials in form of sintered blocks [1-3]. However, the limited tritium recovery and thermal and radiation stability of sintered blocks, soon led to an alternative breeder configuration that of a pebble bed, where the breeder is in the form of small pebbles ( 0.5 to $\sim 1.5 \mathrm{~mm}$ diam.) and mixed with even smaller pebbles $(0.1$ to $0.3 \mathrm{~mm})$ in order to maximize packing fractions $(\mathrm{PF})$. The fundamental issue of using a sphere-pack configuration is the low thermal conductivity and the inherently low PF $(<72 \%$ dense) results in low lithium to structure volume fractions, which result in marginal tritium breeding ratios (TBRs).

A new cellular breeder material is presented here with substantially higher densities and thermal conductivities relative to pebble beds. The cellular breeder contains a network of interconnected micro-channels, which are engineered during the fabricated process and which facilitate tritium release rates similar to those of pebble beds. Aside from increased density and thermal conductivity, high temperature sintering is eliminated and thermal durability is increased due to the morphology of the cellular breeder. Cellular breeders can be fabricated using any lithium-containing ceramic material, however here we report on the development of lithium zirconate $\left(\mathrm{Li}_{2} \mathrm{ZrO}_{3}\right)$ as the first cellular breeder with $\mathrm{Li}_{2} \mathrm{TiO}_{3}$ to follow shortly.
Previous analysis and experiments on sintered blocks identified thermal stress induced cracking, as a feasibility issue leading to physical and thermal integrity concerns [4]. However, the newly developed cellular material appears to be stronger in that it is capable of sustaining prototypical temperature gradients without cracking. Because tritium release is a critical aspect of the solid breeder, a substantial fabrication effort was focused on control of micro-channel size and we show that the diameters of the tritium micro-purge channels can be tailored to meet breeder density requirements. A series of deuterium thermal desorption tests were conducted at Idaho National Laboratory (INL), which showed that release rates are efficient and comparable to those of packed beds. These preliminary characterizations encourage further development of cellular breeder materials for solid breeder blanket applications.

\section{Cellular Breeder Fabrication}

\subsection{Fabrication Process}

Figure 1 shows the schematic of cellular breeder fabrication. The new breeder is constructed by casting breeder material into a highly porous open-cell carbon foam skeleton. The carbon skeleton is then removed by oxidation, leaving a three-dimensional (3D) network of finely spaced interconnected and open tritium purge channels. Processing begins with reticulated vitreous carbon (RVC) foam. Various pore sizes are available from 3 to 130 pores per linear inch (ppi). RVC foam is 3 vol.\% dense ( $97 \%$ open porosity), independent of pore size. The

Author's email: shahrams@ucla.edu 
thickness of the foam ligaments is then increased by infiltrated with carbon using chemical vapor infiltration (CVI) until the material reaches a desired density $(\sim 10$ vol.\%). This step allows to vary the purge channel diameter/volume. Next, the breeder material, in powder form, is heated above its melting point and melt infiltrated (cast) into the carbon foam. The final step is to burn out, oxidize the carbon foam, leaving behind an interconnected network of purge channels for tritium. Just a single infiltration step is needed to completely fill the void space in the foam. Components up to $30 \mathrm{~cm}$ square $\times 7 \mathrm{~cm}$ thick have been fabricated.

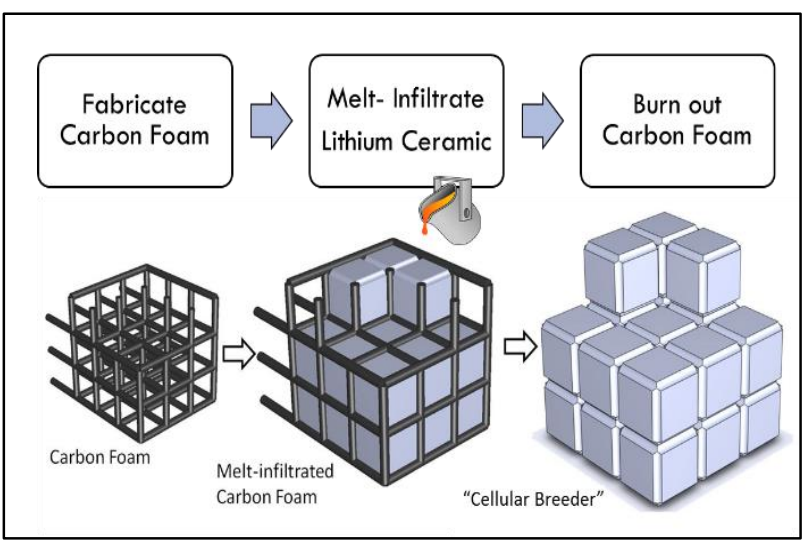

Fig. 1: Schematic of cellular breeder fabrication process.

\subsection{Foam Protective Interlayer}

Prior to melt-infiltration of the lithium-containing ceramic, a thin metal or ceramic interlayer is first applied to the foam to protect ligaments from reacting with the molten ceramic. A thin tungsten metal layer was applied by chemical vapor deposition to protect the foam during melt infiltration and to promote wicking of the molten ceramic. Figures 2A-C show 45- and 65-ppi tungstencoated carbon foams used to fabricate cellular breeder specimens and a cut section of an individual 65-ppi carbon foam ligament coated with tungsten. The tungsten interlayer must be thick enough to prevent reaction between the underlying carbon foam and the lithium compounds but thin enough to prevent excessive strengthening of the foam. If the foam is too strong, stresses caused by thermal expansion mismatch with the lithium compound occur, resulting in micro-cracking of the lithium compound during solidification. The foam must be sufficiently weak that micro-cracking during solidification occurs in the foam ligaments rather than in the lithium compound. An optimal amount of tungsten of a few vol. \% was established to prevent micro-cracking in the lithium compound. Some of the tungsten is removed during foam removal and the rest uniformly diffuses throughout the structure.

This tungsten should not inhibit permeation of hydrogen. However, neutron irradiation of this tungsten will create bulk defects that will retain tritium. The impact of tungsten on tritium release and microstructure evolution in the $\mathrm{Li}_{2} \mathrm{ZrO}_{3}$ cellular breeder material should be investigated further via neutron irradiation tests.
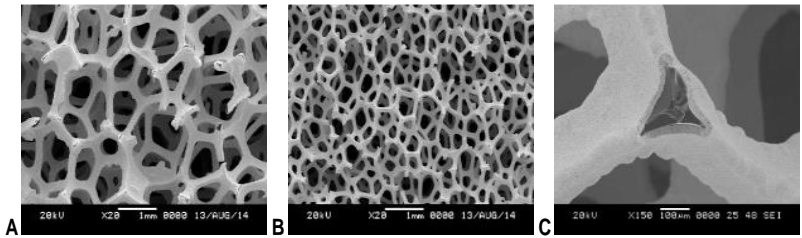

Fig. 2A-C: SEM images of W-coated carbon foams (A) 45-ppi, (B) 65-ppi, and (C) cut individual 65-ppi carbon foam ligament (dark triangle) with W (light coating).

\subsection{Initial Cellular Breeder Samples}

Through melt process optimization (temperature, pressure, time) and use of timed vibrations, $\mathrm{Li}_{2} \mathrm{ZrO}_{3}$ cellular breeder specimens with high overall densities of $\sim 90 \%$ were produced. Figures $3 \mathrm{~A}-\mathrm{D}$ show SEM images of a $\mathrm{Li}_{2} \mathrm{ZrO}_{3}$ cellular breeder sample after removal of the carbon foam by oxidation. $\mathrm{Li}_{2} \mathrm{ZrO}_{3}$ was melt infiltrated into a 1 " diameter $\times 0.180$ " thick carbon foam, after a thin tungsten interlayer was first deposited on the foam. The cellular breeder has an overall density of $\sim 92.9 \%$ or a total porosity of about $8 \%$, which consists of the microchannels and closed pores. The channel spacing shown in Fig. 3 is similar to that in current pebble beds. The microchannel width is about $\sim 100 \mu \mathrm{m}$ and the average cell diameter $\left(\mathrm{Li}_{2} \mathrm{ZrO}_{3}\right)$ is $\sim 850 \mu \mathrm{m}$, which translates to a maximum tritium diffusion length of $\sim 425 \mu \mathrm{m}$. The geometric features of the $\mathrm{Li}_{2} \mathrm{ZrO}_{3}$ cellular breeder shown in Fig. 3 are relatively similar to those of pebble beds.
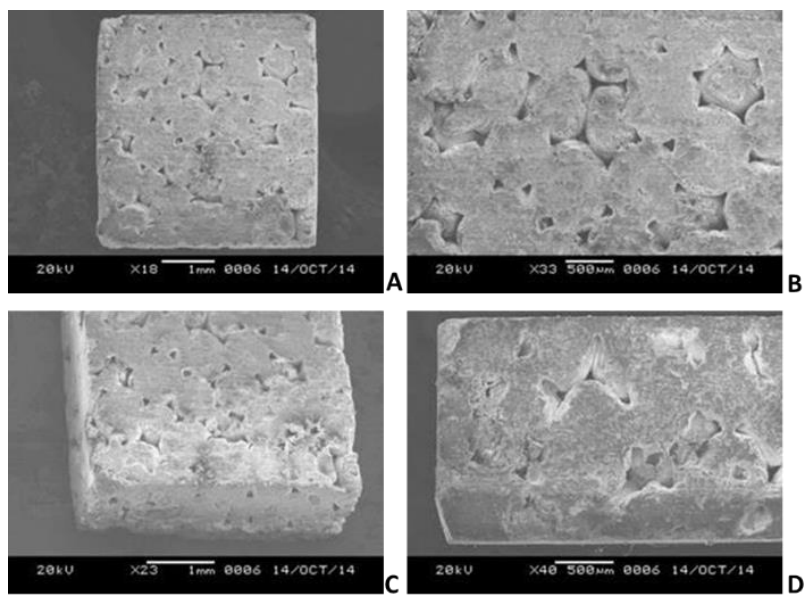

Fig. 3A-D: SEM images of nominally $\sim 90 \%$ dense $\mathrm{Li}_{2} \mathrm{ZrO}_{3}$ cellular breeder development specimen [scale bars: 1-mm (A, C); 500- $\mu \mathrm{m}(\mathrm{B}, \mathrm{D})]$.

\section{Cellular Breeder Characterization}

\subsection{Tomography}

Efficient tritium release, i.e. release by convection requires a stable network of interconnected microchannels that lead to the free surface of the cellular breeder. To verify the network of interconnected microchannels, several $\mathrm{Li}_{2} \mathrm{ZrO}_{3}$ cellular breeder samples were sent for micro-tomography scanning at the HighResolution X-ray Computed Tomography Facility at the University of Texas at Austin [5], which has an X-ray 
energy of $15 \mathrm{kV}$ with a resolution of $5 \mu \mathrm{m}$. The dimensions of the $88.7 \%$ dense specimen were $0.165 \times 0.165 \times 0.071$ ", with a weight of $0.1289 \mathrm{~g}$, a bulk density of $4.069 \mathrm{~g} / \mathrm{cm}^{3}$, a tungsten density within the specimen of $0.386 \mathrm{~g} / \mathrm{cm}^{3}$, and $\mathrm{Li}_{2} \mathrm{ZrO}_{3}$ density within the specimen of $3.683 \mathrm{~g} / \mathrm{cm}^{3}$. An SEM image of a specimen is shown in Figure 4A-B along with a superimposed tomography scan showing the structure of the interconnected micro-channels within the cellular breeder and Fig. 5 shows details of a tomography scan highlighting the structure of the interconnected microchannels.

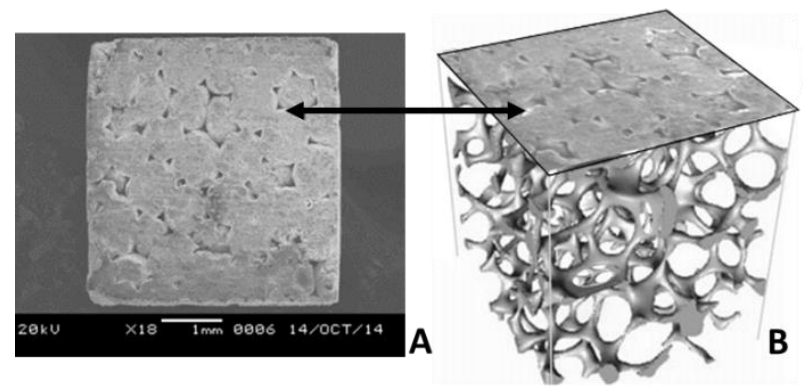

Fig. 4A-B: SEM image of cellular breeder (A) and tomography scan showing network of interconnected micro-channels (purge channels) within (B).

The micro-channels shown in Fig. 4 and 5 were made visible by post processing of tomography scans. It is interesting to note that the structure of the micro-channels is a "negative print" of the original carbon foam used for melt infiltration. The low level of closed porosity can be seen as small, scattered brown spots in Fig. 5.

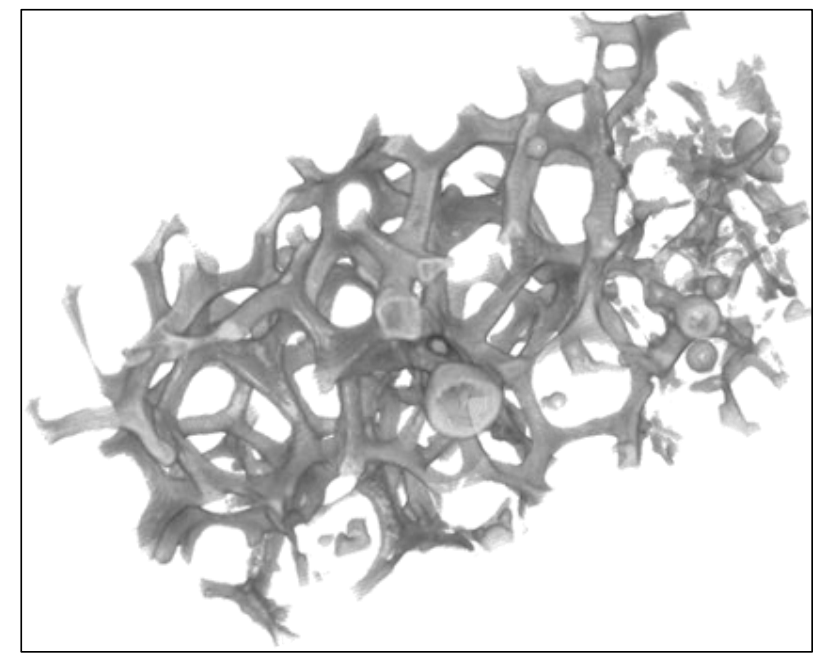

Fig. 5: X-ray tomography scan $\mathrm{Li}_{2} \mathrm{ZrO}_{3}$ cellular breeder (65-ppi, $92.9 \%$ dense), showing structure of open interconnected microchannels inside the breeder.

The maximum distance between tritium purge channels (micro-channels) in the cellular breeder is dictated by the pore size of the foam skeleton used during construction. To date, a foam pore size of $0.8 \mathrm{~mm}$ has been successfully used in cellular breeder fabrication, resulting in a maximum tritium diffusion distance of 0.4 $\mathrm{mm}$ (comparable to current solid breeder pebble diameter). In future work, processing may be feasible using foam with a $0.5 \mathrm{~mm}$ pore size which is available, yielding a further reduced tritium diffusion distance of $0.25 \mathrm{~mm}$.

\subsection{Composition Analysis}

Chemical analysis was performed to determine if the lithium content was reduced as a result of melt processing. The results of XPS compositional analysis for lithium, oxygen, zirconium, and carbon are shown in Table I. After melt processing, the lithium level did not appear to change significantly from that of the virgin $\mathrm{Li}_{2} \mathrm{ZrO}_{3}$ powder. The as received powder contains residual lithium carbonate, which is one of the precursors used to manufacture lithium zirconate. During melt processing the carbon content decreased, because most of the lithium carbonate impurity was removed during the purification process. The lithium content for all specimens was significantly higher than that of stoichiometric $\mathrm{Li}_{2} \mathrm{ZrO}_{3}$ (33 at. \%) and the oxygen content was lower than that of stoichiometric $\mathrm{Li}_{2} \mathrm{ZrO}_{3}$ (50 at. \%). The zirconium content of the cellular specimens was close to that of stoichiometric $\mathrm{Li}_{2} \mathrm{ZrO}_{3}(16$ at. \%). The compositional analysis showed that melt processing does not significantly alter the lithium concentration. The tungsten level in $90 \%$ dense cellular breeder samples $381 \mathrm{~T}$ and $380 \mathrm{~T}$ was determined by EAG using secondary ion mass spectroscopy to be $\sim 2$ at. $\%$ and $\sim 0.6$ at. $\%$, respectively.

The IGA results for $\mathrm{C}$ and $\mathrm{O}$ content performed by EAG on the same three specimens are shown in Table II. The $\mathrm{O}$ content of the $\mathrm{Li}_{2} \mathrm{ZrO}_{3}$ cellular breeder specimens was virtually the same as that of the as-received $\mathrm{Li}_{2} \mathrm{ZrO}_{3}$ powder, similar to the results of oxygen analysis by XPS. The carbon concentration of the $\mathrm{Li}_{2} \mathrm{ZrO}_{3}$ cellular breeder specimens was slightly higher than that of the as-received powder, which is different from the results of $\mathrm{C}$ analysis by XPS in which the carbon concentration of the asreceived powder was shown to be several times higher.

Table I: Compositional Analysis of $\mathrm{Li}_{2} \mathrm{ZrO}_{3}$ (at.\%)

\begin{tabular}{lcccc}
\hline Specimen & $\mathrm{Li}$ & $\mathrm{O}$ & $\mathrm{Zr}$ & $\mathrm{C}$ \\
\hline 381T Cellular (93.0 \% dense) & 52.2 & 28.1 & 15.2 & 1.3 \\
380T Cellular (90.5\% dense) & 52.6 & 26.8 & 16.2 & 0.3 \\
$\mathrm{Li}_{2} \mathrm{ZrO}_{3}$ Powder(Alfa Aesar) & 47.8 & 34.4 & 10.5 & 6.3 \\
\hline
\end{tabular}

Table II: IGA Results for Cellular $\mathrm{Li}_{2} \mathrm{ZrO}_{3}$ (wt.\%)

\begin{tabular}{lcc}
\hline Specimen & Carbon & Oxygen \\
\hline 381T Cellular Breeder (93.0 \%) & 790 & 26 \\
380T Cellular Breeder (90.5\%) & 710 & 26 \\
As received $\mathrm{Li}_{2} \mathrm{ZrO}_{3}$ (Alfa Aesar) & 600 & 25 \\
\hline
\end{tabular}

\subsection{Density Measurements}

To determine the bulk density, which includes the solid material, the open porosity (interconnected microchannels), the closed porosity within the bulk breeder material, the absolute density (which includes all solid material and closed pores), and the cellular porosity percentage, cellular breeder samples were sent for mercury intrusion porosimetry and He-pycnometry 
testing. Virtually all specimens were estimated to be $\geq 90 \%$ dense. The amount of tungsten was estimated using EDS compositional analysis. The $\mathrm{Li}_{2} \mathrm{ZrO}_{3}$ density was calculated by subtracting the tungsten density from the bulk density. Density data is summarized in Table III.

The residual tungsten inside the breeder ceramic may result in the formation of tungsten oxides, which are known to interact with hydrogen to form hydrates. However, in the presence of water or tritium oxide at elevated temperatures $\left(>550^{\circ} \mathrm{C}\right)$, tungsten oxides are reduced to the pure metal. It is well-known that in metallic form, tungsten does not inhibit permeation of hydrogen. The impact of tungsten on tritium release and microstructure evolution in the $\mathrm{Li}_{2} \mathrm{ZrO}_{3}$ cellular breeder material should be investigated further via neutron irradiation tests.

Table III: Densities of 65-ppi Cellular Breeders

\begin{tabular}{ccccc}
\hline Sample & $\begin{array}{c}\text { Bulk } \\
\left(\mathrm{g} / \mathrm{cm}^{3}\right)\end{array}$ & $\begin{array}{c}\text { Tungsten } \\
\left(\mathrm{g} / \mathrm{cm}^{3}\right)\end{array}$ & $\begin{array}{c}\mathrm{Li}_{2} \mathrm{ZrO}_{3} \\
\left(\mathrm{~g} / \mathrm{cm}^{3}\right)\end{array}$ & $\begin{array}{c}\text { Density } \\
(\%)\end{array}$ \\
\hline $371 \mathrm{~T}$ & 4.135 & 0.386 & 3.749 & 90.3 \\
$374 \mathrm{~B}$ & 4.435 & 0.579 & 3.856 & 92.9 \\
$377 \mathrm{~T}$ & 4.255 & 0.482 & 3.773 & 90.9 \\
378B & 4.195 & 0.482 & 3.713 & 89.5 \\
378T & 4.318 & 0.579 & 3.739 & 90.0 \\
$380 \mathrm{~T}$ & 4.237 & 0.482 & 3.755 & 90.5 \\
$381 \mathrm{~T}$ & 4.437 & 0.579 & 3.858 & 93.0 \\
$382 \mathrm{~T}$ & 4.352 & 0.579 & 3.773 & 90.9 \\
\hline
\end{tabular}

\section{Thermal-Mechanical Properties}

\subsection{Thermal Conductivity}

Two high density $\mathrm{Li}_{2} \mathrm{ZrO}_{3}$ cellular breeder specimens were tested for thermal conductivity from RT to $1200^{\circ} \mathrm{C}$. Each contained 2-3 vol.\% tungsten. Thermal diffusivity was determined using laser flash diffusivity and thermal conductivity (Fig. 6) was calculated using the measured specific heat and diffusivity data TPRL [6].

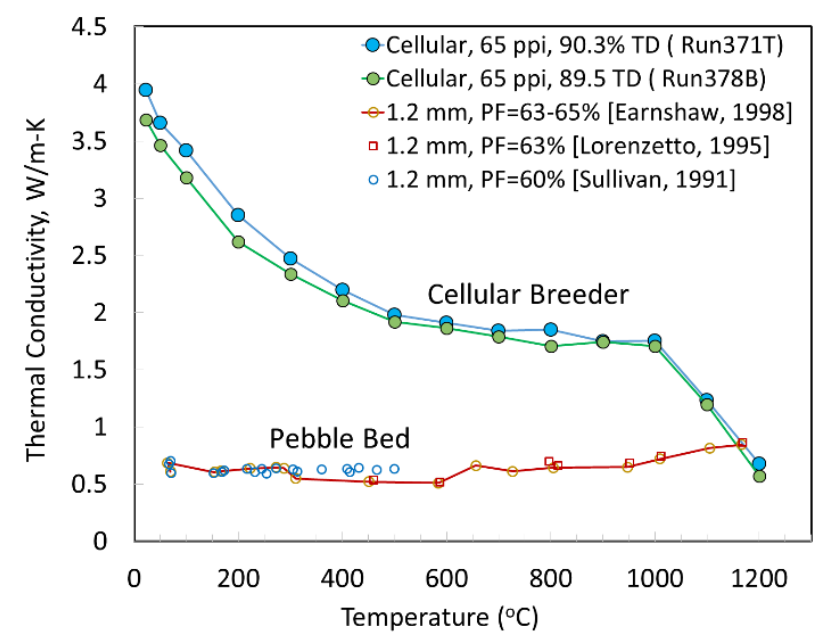

Figure 6: Thermal conductivity of 65-ppi $\mathrm{Li}_{2} \mathrm{ZrO}_{3}$ cellular breeder samples $371 \mathrm{~T}$ (90.3\% dense) and 378B (89.5\% dense); $\mathrm{Li}_{2} \mathrm{ZrO}_{3}$ pebble bed data are shown for comparison.

\subsection{Cyclic Compression Testing}

Cyclic compression tests comprised three samples (380T, 377T, and 378T) on 90.5\% dense, 65-ppi $\mathrm{Li}_{2} \mathrm{ZrO}_{3}$ cellular breeder material at room temperature and $750^{\circ} \mathrm{C}$. All specimens were tested under a cyclic loading pattern of 5, 10, and $15 \mathrm{MPa}$. Two loading/unloading cycles were applied at each pressure at a constant loading/unloading rate of $1 \mathrm{MPa} / \mathrm{min}$. Stress-strain curves for sample 378T is shown in Fig. 7. Nonlinear elastic behavior was observed for both the loading and unloading paths in all samples. After the completion of unloading, a residual strain appeared that increased with applied pressure.

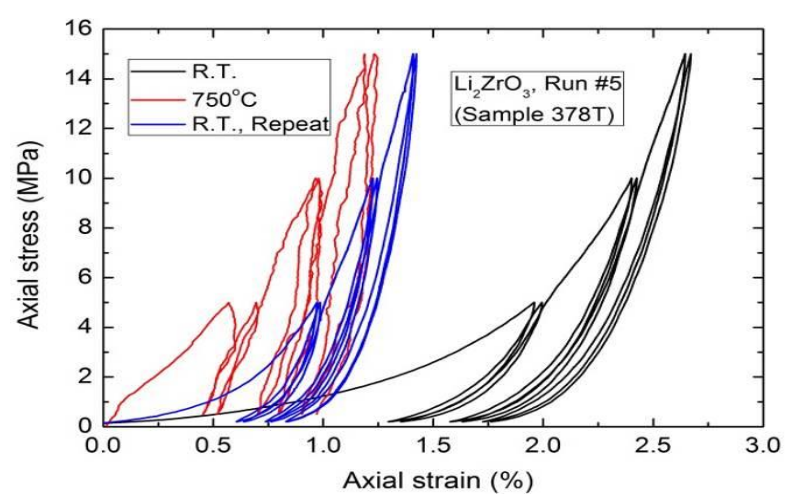

Figure 7: Stress-strain curves for $\mathrm{Li2ZrO} 3$ cellular breeder at RT and $750^{\circ} \mathrm{C}$ (378T: 65 -ppi, 90.0\% dense).

For a peak load of $15 \mathrm{MPa}$, the maximum residual strain was $1.23 \%$, whereas the residual strains for the peak loads of 5 and $10 \mathrm{MPa}$ were $0.90 \%$ and $1.09 \%$, respectively. Because of the material hardening effect, the modulus increased with applied load. The stress-strain data from the unloading paths were used to evaluate Young's modulus. A modulus of $1.9 \mathrm{GPa}, 2.9 \mathrm{GPa}$, and $3.3 \mathrm{GPa}$ were found at the peak loads of 5,10 , and 15 $\mathrm{MPa}$, respectively. Table-IV lists the estimated Young's modulus at test temperatures and loads.

Table-IV: Young's Modulus of Li2ZrO3 Cellular Breeders

\begin{tabular}{|c|c|c|c|c|}
\hline & \multicolumn{4}{|c|}{ Young's Modulus, GPa } \\
\hline & Part 380T & Part 377T & Part 37 & \\
\hline \multicolumn{2}{|c|}{ Room Temperature } & & Run-1 & Run-1 \\
\hline $5 \mathrm{MPa}$ & $2.7(\mathrm{a})$ & 1.6 & $1.4(\mathrm{~b})$ & $2.1(\mathrm{a})$ \\
\hline $10 \mathrm{MPa}$ & $4.2(\mathrm{a})$ & 1.9 & 1.9 (b) & $3.1(\mathrm{a})$ \\
\hline $15 \mathrm{MPa}$ & $5.0(\mathrm{a})$ & 2.1 & $2.5(\mathrm{~b})$ & 4.2(a) \\
\hline \multicolumn{5}{|l|}{$750^{\circ} \mathrm{C}$} \\
\hline $5 \mathrm{MPa}$ & 2.5 & 2 & \multicolumn{2}{|c|}{1.9} \\
\hline $10 \mathrm{MPa}$ & (c) & 2.7 & \multicolumn{2}{|c|}{2.9} \\
\hline $15 \mathrm{MPa}$ & (c) & 3.1 & \multicolumn{2}{|c|}{3.3} \\
\hline
\end{tabular}

(a) Obtained after $750 \mathrm{C}$ test; (b) Obtained before $750 \mathrm{C}$ test

(c) Could not be determined due to specimen thickness

\subsection{Applied Thermal Gradient}

As a preliminary confirmation that $\mathrm{Li}_{2} \mathrm{ZrO}_{3}$ cellular breeder could withstand expected thermomechanical loads relevant to fusion reactor environments, testing was performed under high temperature operation $\left(\sim 600^{\circ} \mathrm{C}\right)$ and high thermal gradient $\left(\sim 40^{\circ} \mathrm{C} / \mathrm{mm}\right)$ conditions. The thermal loads are expected to induce significant stress and 
strain in the material. The tests were performed using the Zwick test stand with a customized piston $\operatorname{rod}$ (UCLA). A disk of $\mathrm{Li}_{2} \mathrm{ZrO}_{3}$ cellular breeder (sample 381T, 93\% dense) was placed in the compression/tension test frame and placed under $400 \mathrm{~N}$ of compression. A furnace around the test frame was used to heat the sample to $\sim 600^{\circ} \mathrm{C}$, and an auxiliary heater on the upper test frame piston was used to produce a temperature differential across the sample of $\sim 200^{\circ} \mathrm{C}$. At steady-state average temperature and temperature gradient, the sample was loaded in compression to 5,10, and $15 \mathrm{MPa}$ with five cycles at each load (Fig. 8). The loading cycles were selected to first approximate the expected thermal stress loading in a fusion reactor environment $(5 \mathrm{MPa})$ and then to successively increase to 10 and $15 \mathrm{MPa}$ to approximate the expected maximum stresses.

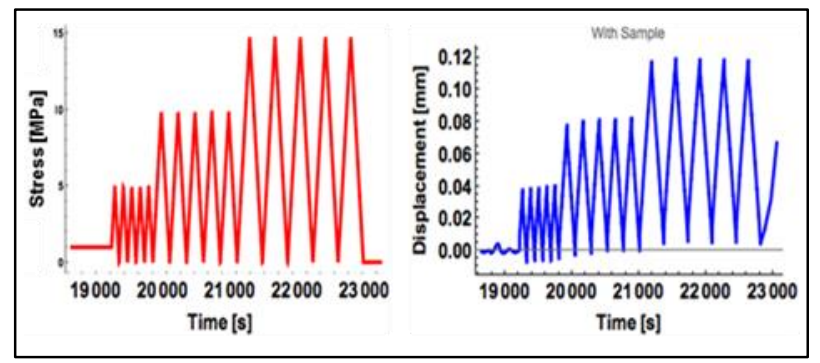

Figure 8: Cyclic loading in force control (A) and crosshead displacement during cyclic testing (B).

Figure 9 shows average temperature as function of time (A) and temperature differential per millimeter developed across sample (B). The axial thermal expansion was $\sim 2.5 \mu \mathrm{m}$, or $\sim 650$ micro-strain. Based on previous tests in this program, the Young's modulus at these temperatures was expected to be $\sim 5 \mathrm{GPa}$, leading to an estimated thermally induced stress of $3.25 \mathrm{MPa}$. After mechanical load cycling, the sample was removed and inspected and no changes were observed. The thermal gradient tests results indicate that the $\mathrm{Li}_{2} \mathrm{ZrO}_{3}$ cellular breeder material could withstand expected fusion reactor thermal loading conditions. The tests were not an exhaustive qualification of the material for use in a fusion environment, but server only as an indication that the material merits further development.

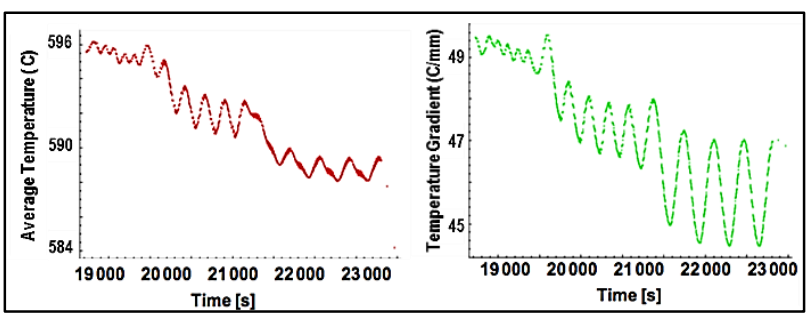

Figure 9: Average temperature as function of time and temperature differential per millimeter developed across sample.

\section{Deuterium Absorption-Desorption Test}

To provide an initial indication of tritium diffusion in the cellular breeder, a deuterium absorption/desorption experiment was performed at INL. Personnel at the Safety and Tritium Applied Research facility at INL built a static deuterium gas absorption system (SGAS) to evaluate deuterium gas absorption and desorption behavior in plasma-facing components under sub-atmospheric hydrogen/deuterium pressure $(<1 \mathrm{~atm})$ at elevated temperature $\left(\leq 950^{\circ} \mathrm{C}\right)$. Ultramet delivered four 65-ppi $\mathrm{Li}_{2} \mathrm{ZrO}_{3}$ cellular samples ranged in density from 82 to 93 $\%$ (each specimen contained $\sim 0.5 \mathrm{~g} / \mathrm{cm}^{3}$ tungsten). Due to time constraints, only one $\mathrm{Li}_{2} \mathrm{ZrO}_{3}$ cellular breeder $(\mathrm{P} / \mathrm{N}$ $382-1,82 \%$ dense) was tested for deuterium absorption and desorption behavior. To remove residual moisture $\left(\mathrm{H}_{2} \mathrm{O}\right)$, the sample was outgassed under vacuum $\left(\sim 1.3 \times 10^{-5} \mathrm{~Pa}\right)$ at elevated temperature $\left(950^{\circ} \mathrm{C}\right)$ for more than 5 hours before the absorption test and then held under vacuum $\left(\sim 1.3 \times 10^{-5} \mathrm{~Pa}\right)$ at room temperature for more than 10 days.

Figure 10 shows thermal desorption behavior of deuterium-containing species $\left(\mathrm{HD}, \mathrm{D}_{2}, \mathrm{HDO}, \mathrm{D}_{2} \mathrm{O}\right)$ after $950^{\circ} \mathrm{C}$ exposure with $720-\mathrm{Pa}$ deuterium pressure. Because a calibrated source of HDO or D2O was unavailable, the initial desorption behavior was performed without a calibrated source. A significant amount of $\mathrm{H} 2 \mathrm{O}$, HDO, and $\mathrm{D} 2 \mathrm{O}$ existed in the $\mathrm{Li}_{2} \mathrm{ZrO}_{3}$ even after a 1-hour bakeout. Most of the deuterium-containing species were desorbed as $\mathrm{HDO}$ and $\mathrm{D} 2 \mathrm{O}$ and peaked at $\sim 500^{\circ} \mathrm{C}$, whereas the $\mathrm{HD}$ and $\mathrm{D} 2$ peaked at $\sim 700^{\circ} \mathrm{C}$. The rapid release rates measured by INL indicate that the geometric features of the cellular structure do not inhibit deuterium release.

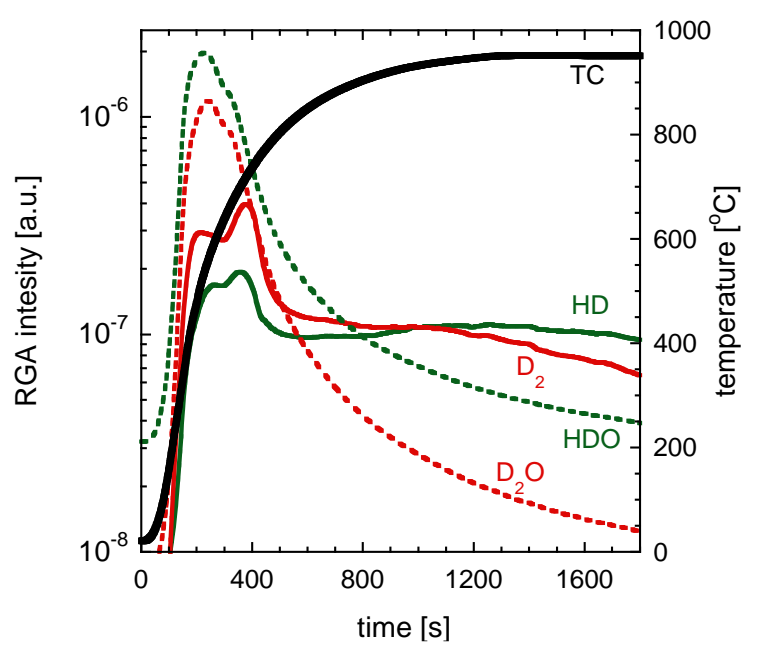

Figure 10: Desorption behavior of deuterium-charged cellular breeder sample 825 dense) following $950^{\circ} \mathrm{C}$ exposure with 720 $\mathrm{Pa}$ deuterium pressure for $2700 \mathrm{~s}$.

\section{Adjusting Cellular Morphology}

\subsection{Decreasing Breeder Cell Size}

Tritium release rates are influenced by the length of the diffusion path from the center of a breeder cell to an open micro-channel.

To decrease the average tritium diffusion length, from the center of a breeder cell to an interconnected microchannel a 65-ppi foam was used. The 65-ppi foam was chosen to take advantage of the smaller pore size $(400 \mu \mathrm{m}$ 
vs. $800 \mu \mathrm{m}$ for $45 \mathrm{ppi}$ ), which leads to a shorter tritium diffusion distance in the finished cellular breeder

\subsection{Tailoring Micro-Channel Diameter}

Control of geometric features of the network of interconnected micro-channels is a critical aspect for optimization of cellular breeder material performance. For example, with an increase in channel diameter the density of breeding material decreases and thus tritium production will be reduced. On the other hand, if channels are too small, the purge flow pressure drop might become infinitively large. Two samples with different channel size were produced of $\sim 80 \mu \mathrm{m}$ and $\sim 150 \mu \mathrm{m}$ diameter, which increased the volume of the interconnected microchannels by roughly a factor of 3.5 times .

\subsubsection{Small Micro-Channels}

Figures 11A-D show $\mathrm{Li}_{2} \mathrm{ZrO}_{3}$ cellular breeder fabricated using 65-ppi carbon foam but with no pyC, resulting in small-diameter tritium purge channels of about $80 \mu \mathrm{m}$. The material was estimated to be $88 \%$ dense, with the $12 \%$ porosity composed of $3 \%$ carbon foam $/ 4 \%$ tungsten interlayer / $5 \%$ residual porosity related to unfilled foam cells and small pores within the solid $\mathrm{Li}_{2} \mathrm{ZrO}_{3}$. After additional process optimization, $\mathrm{Li}_{2} \mathrm{ZrO}_{3}$ cellular breeder was fabricated in excess of $90 \%$ dense.
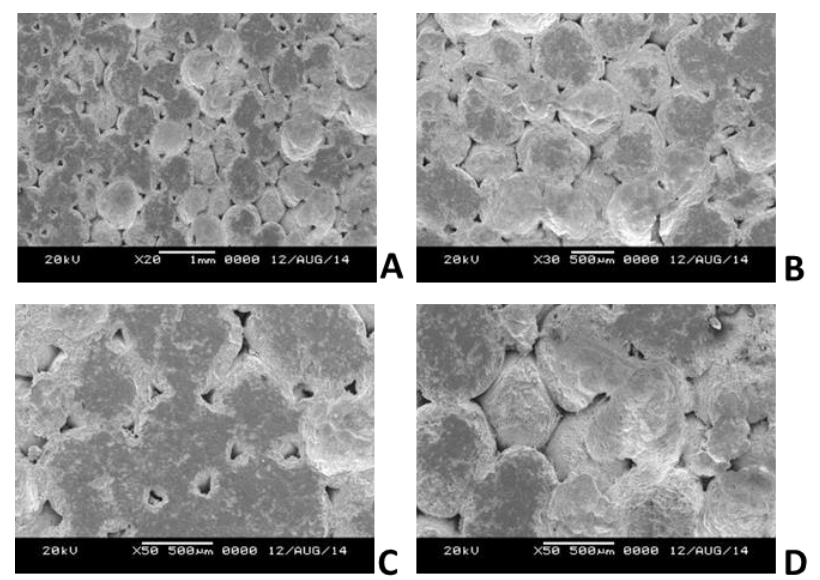

Figure 11A-D: SEM images of $\mathrm{Li}_{2} \mathrm{ZrO}_{3}$ cellular breeder fabricated using 65-ppi carbon foam ( $88 \%$ dense) [scale bar: 1 $\mathrm{mm}(\mathrm{A}), 500 \mu \mathrm{m}(\mathrm{B}-\mathrm{D})]$.

\subsubsection{Large Micro-Channels}

Figures 12A-D shows the $\mathrm{Li}_{2} \mathrm{ZrO}_{3}$ cellular breeder material made using 65-ppi carbon foam, but with a 10 vol\% pyC coating, before application of the protective tungsten layer, as a means of increasing the foam ligament diameter, which ultimately increases the diameter of the network of interconnected passages (tritium purge channels). This approach demonstrated the tailor ability of the fabrication process through control of the foam ligament diameter as well as ppi (pores per linear inch). The material was estimated to be $78 \%$ dense, with a $22 \%$ porosity composed of the $3 \%$ carbon foam $/ 10 \%$ pyC coating $/ 4 \%$ tungsten interlayer $/ 5 \%$ residual porosity related to unfilled foam cells and small pores within the solid $\mathrm{Li}_{2} \mathrm{ZrO}_{3}$. By depositing additional carbon on the foam ligaments, the internal passage diameter in the finished cellular breeder product increased from nominally $80 \mu \mathrm{m}$ to $200 \mu \mathrm{m}$. The ability to tailor the passage diameter to maximize density for tritium generation while keeping purge flow pumping requirements reasonable is a unique characteristic of the cellular breeder.
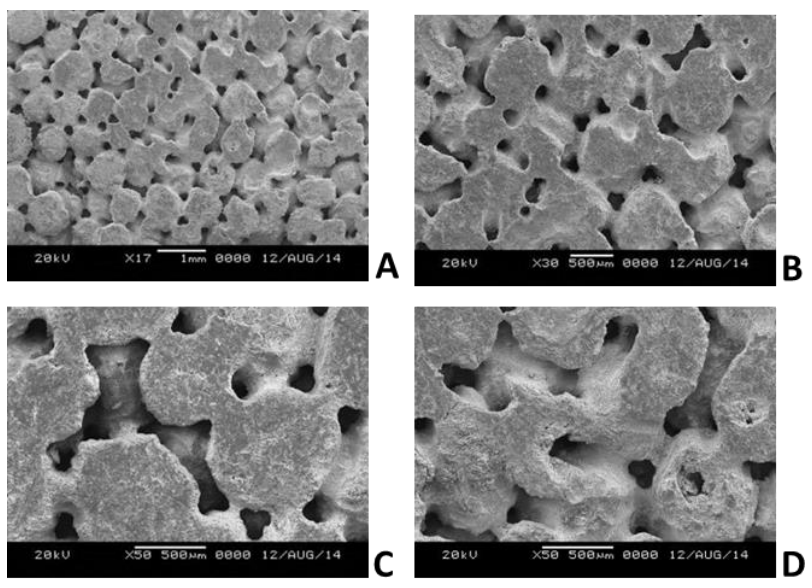

Figure 12A-D: $\mathrm{SEM}$ of $\mathrm{Li}_{2} \mathrm{ZrO}_{3}$ cellular breeder material using 65 -ppi C-foam coated with pyC ( $78 \%$ dense).

\section{Breeder-Wall Contact}

A major concern regarding solid breeder materials is maintaining wall-contact between breeder and cooling structures during operation. The cellular breeder is fabricated as a stand-along block or mono-block configuration, which can be cooled by cooling tubes as shown in Fig. 14A-B.

Regarding the thermal contact between the cellular breeder and the structure, multiple options exist including establishing intimate contact between the two by allowing the breeder to expand into and contact the structure or by mechanical application of a low pressure to ensure contact. Diffusion bonding through brazing is also an option. A brazed interface would yield the greatest thermal contact but would also generate greater stress within the breeder, therefore the blanket would need to be designed to maintain breeder stress at an acceptable level. It should be noted that the cellular breeder offers significant advantages over a pebble bed in terms of thermal contact requirements. The $\mathrm{Li}_{2} \mathrm{ZrO}_{3}$ cellular breeder is thermally stable to near the $1750{ }^{\circ} \mathrm{C}$ fabrication temperature, therefore the cooling requirements are much less restrictive than those for the much lower use temperature pebble beds. In addition, the cellular breeder is nominally $90 \%$ solid ( $10 \%$ porous), therefore the surface area contacting the structure, whether through intimate contact or brazing, is far greater than the area of deformed pebbles contacting the structure in a pebble bed.

Fig. 14A-B shows a solid model of a cellular breeder mono-block with a coolant tube and coefficient of thermal expansion (CTE) contours as a function of temperature. The higher CTE of the F82H tube relative to the breeder 
block results in positive contact forces. This configuration is similar to $\mathrm{W}$-mono-blocks and $\mathrm{Cu}$-tubing under development for divertor applications.

The CTE of the $\mathrm{Li}_{2} \mathrm{ZrO}_{3}$ cellular breeder is higher than that of $\mathrm{F} 82 \mathrm{H}$ steel $\left(\mathrm{F} 82 \mathrm{H}: 1.27 \times 10^{-5} / \mathrm{K}, \quad \mathrm{Li}_{2} \mathrm{ZrO}_{3}\right.$ : $1.75 \times 10^{-5} / \mathrm{K}$ at $700^{\circ} \mathrm{C}$ ). Based on the thermal expansion mismatch, the gap between the coolant tube and the breeder mono-block can be tailored to create desired contact forces during operation.

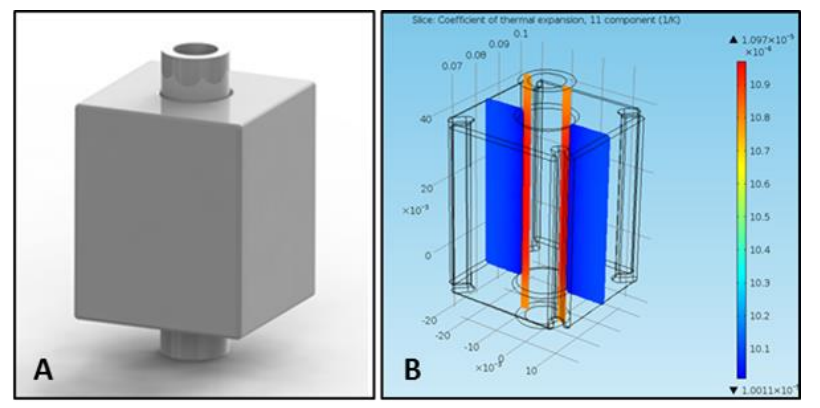

Figure 14A-B: (A) Solid model of a cellular breeder mono-block and coolant tube; (B) CTE contours as a function of temperature in breeder and $\mathrm{F} 82 \mathrm{H}$ tube.

\section{Summary}

A new cellular solid breeder material has been developed based on melt-infiltration of lithiumcontaining ceramic material into highly porous open-cell carbon foam. Following melt-infiltration and solidification the carbon foam is removed by oxidation. The process leaves a $\sim 90 \%$ dense robust freestanding breeder material which contains an internal network of interconnected micro-channels for efficient tritium release. Thermal conductivity is substantially increased (2 to 3 times) relative to pebble beds; high temperature sintering is eliminated; and thermal durability is increased.

Processing conditions were established for fabrication of $\sim 93 \%$ dense lithium zirconate $\left(\mathrm{Li}_{2} \mathrm{ZrO}_{3}\right)$ cellular breeder material with adjustable micro-channel size and volume selected in accordance with tritium release requirements. High temperature $\left(\sim 750^{\circ} \mathrm{C}\right)$ cyclic compression tests demonstrated good structural integrity (no cracking) and low Young's modulus of $<5 \mathrm{GPa}$. Cyclic thermal testing with thermal gradients of about $40{ }^{\circ} \mathrm{C} / \mathrm{mm}$ did not results in cracking, indicating good resistance to thermal stress caused by prototypical fusion relevant temperature loads. Deuterium absorptiondesorption tests performed at INL demonstrated release rates that were comparable with those from pebble beds of similar characteristic T-diffusion lengths.

Thermo-mechanical characterizations, and deuteriumrelease data of the new cellular solid breeder material with a network of interconnected open micro-channels were presented. The higher density ( $\sim 90 \%$ solid) and the higher thermal conductivity $(\sim 2$ to $3 \times)$ of the cellular breeder relative to pebble bed configurations, along with its efficient tritium release could enhance solid breeder blanket performance and increase tritium breeding ratios.
The cellular breeder can be fabricated in block configuration, which can be cooled using tubes with reliable contact by brazing or based on thermal expansion mismatch between breeder and steel tubes.

\section{Acknowledgments}

This work was sponsored by the U.S. Department of Energy (DOE), Office of Science, Fusion Energy Sciences (FES) under the SBIR grant DE-SC0007495 mod-001. The DOE Program Official was Edward J. Stevens. The authors greatly appreciate the tomography analysis by Dr. Jessie Maisano at the University of Texas High-Resolution X-ray Computed Tomography Facility, Austin Texas, and thermal measurements performed by Dr. Robert Larson at TPRL, Inc. West Lafayette, IN 47906 Purdue University.

\section{References}

[1] Dale L. Smith, Evaluation of candidate blanket materials for fusion reactor blanket applications, J. Nucl. Mater., Volume 122, Issue 1, 1984, Pages 51-65, ISSN 0022-3115

[2] Argonne National Laboratory, A Demonstration Tokamak Power Plant Study (DEMO), Fusion power program, M. Abdou et al., September 1982.

[3] ITER-CDA, U.S. National Review of the International Thermonuclear Experimental Reactor ITER, Conceptual Design Activity, D. E. Baldwin, Chair, The University of Texas at Austin, March 1991.

[4] D. L. Smith, et al., Blanket Comparison and Selection Study, Final Report, ANL/FPP-84-1, September 1984.

[5] Jessie Maisano, UTCT, Department of Geological Sciences, University of Texas at Austin, Austin, TX 78712.

[6] Robert Larson, Thermophysical Properties of Two $\mathrm{Li}_{2} \mathrm{ZrO}_{3} \quad$ Samples: TPRL-5277, Thermophysical Properties Research Laboratory (TPRL), Inc., West Lafayette, IN 47906, January 2015.

[7] J. Earnshaw, F. Londry, P. Gierszewski, "The Effective Thermal Conductivity of Bed of $1.2 \mathrm{~mm}$ Lithium Zirconate Spheres in Helium”, Fusion Tech., 33, (1998).

[8] P. Lorenzetto, P. Gierszewski, G. Simbolotti, “A European Proposal for an ITER Water-cooled Solid Breeder Blanket“, Fusion Eng. \& Design, 27, 423, (1995).

[9] J. Sullivan et al. "Canadian Ceramic Breeder Sphere-pac Technology: Capability and Recent Results“, Fusion Eng. \& Design, 17, 79, (1991). 